\title{
EDUCATION IN THE CONTEXT OF IT REALITY
}

\author{
Branislav Banić1*, \\ Ilija Banić2 \\ Siniša Jovanović ${ }^{3}$, \\ Milica Andevski ${ }^{4}$, \\ Pavle Stojanović 3
${ }^{1}$ Faculty of Physical Education and Sports Management, Singidunum University, Belgrade, Serbia \\ ${ }^{2}$ Faculty of Sports and Physical \\ Education, \\ Leposavić, Serbia \\ 3Primary school Milan llić Čiča, \\ Aranđelovac, Serbia \\ ${ }^{4}$ Faculty of Philosophy, \\ Novi Sad, Serbia
}

\section{Correspondence:}

Branislav Banić

e-mail:

bbanic@singidunum.ac.rs

\begin{abstract}
:
The technological reality of the global village has expanded man's senses and led him to a new translation and revaluation of patterns of behavior, mutual communication, culture, lifestyle at the speed with which new technology improves and marks reality. In the new context of shaping knowledge, attitudes and values, education appears as a mediator of the individual and the community, desires and possibilities, freedoms and norms. Education has a role to enable those who learning to understand contemporary culture and society, to shape their own identity and resistance to media manipulation, to respond alternatively, creatively to the challenges of modern mediated and alienated society. The process of education becomes more complex because in addition to technological configurations, numerous social and institutional factors participate as bearers of power, influence and manipulation in the system of mediation. In the context of the above mentioned, media didactics and media education are constituted as synchronous sciences that interact mutually and develop concepts of critical analysis of one's own environment as well as the content of contemporary media and consumer culture, its meanings and effects. The critical perspective opens with the constitution of critical media pedagogy based on solid communication, sociological and philosophical foundations and knowledge of the ontological, epistemological and value dimensions of each media mediation and education.
\end{abstract}

\section{Keywords:}

education, media, pedagogy, technology, internet.

\section{INTRODUCTION}

By the nature of its social mission, education is always a kind of mediation between the man and the world, between truth and reality, between being and thinking. That is why the whole school and educational system necessarily has its intermediary or media dimension. In an effort to reach a set ideal or pattern of knowledge, attitudes and values, the school has always emerged as a mediator between the individual and the community, desires and opportunities, freedoms and norms. Not only education, but all other spheres of human life, depend on intermediaries and the rules they establish. 
Human knowledge and the overall results of cognitive processes are largely determined by intermediaries or media that are placed between the subject and the object of cognition. McLuhan's maxim "The medium is the message" is valid not only for the world of journalism, but also for the world of science and scientists [1] and the educational process becomes complicated when we know that, in addition to technological configurations numerous social and institutional factors participate in the mediation system as holders of influence and manipulation. In the Media Manifestos, the French mediologist Debray points out: "The mediator creates the law".

Mediation determines the nature of the message; the relationship takes precedence over the being. In other words, it is bodies that think, not mind. The compulsion of incorporation produces corporations - those intermediary bodies and institutions of knowledge, standardized and normative, which we call schools, churches, parties, associations, thinkers' societies, etc. [2]. Critical media pedagogy must therefore be based on solid communication, sociological and philosophical foundations and knowledge of the ontological, epistemological and value dimensions of any media mediation.

The main purpose and mission of critical media pedagogy would be to enable students and all citizens to understand contemporary culture and society, to create their own identity and resistance to media manipulation, as well as to encourage media to create alternative and creative forms of culture in order to transform contemporary media and alienated society: "Critical media pedagogy develops concepts and analyzes that enable readers to analyze the contents of contemporary media and consumer culture critically, discover the meanings and effects of their own culture and thus help them gain control over their own cultural environment. I think that the criticism of culture and media pedagogy requires the application of social theory and that this critical theory of society should also be based on the media and the study of culture as critical methods, in order to provide an essential insight into the structure of modern social life. Thus, this project combines methodological strategies, theories and concepts of both modernist and postmodernist theories, trying to create a critical perspective suitable for analyzing the most important cultural and social phenomena of the modern age." [3].

Pedagogy encounters the phenomenon of the media not only at the aforementioned critical and communicativephilosophical level, but also at the daily, methodological-technical level. We will show that on the example given by the famous German media teacher Tulodziecki. Imagine that a teacher plans to convey and explain the content of the term "park" to his students. He can do this by going with them to some real park near the school; may also process the content of the term park using a park model with trees in a sandbox; furthermore, the teacher can show the students a film or a series of slides about the park; and finally, he has the opportunity to explain verbally the concept of a park to students. Based on this example, it is possible to distinguish at least four forms of presentation of teaching content:

- a real form, which exists in active action in reality, personal encounter with people or in practical relationship with things,

- a form of model, which is represented in the use of reality models or in simulation in role-playing,

- a form of mapping, when information and knowledge are obtained by means of a representation that is true to reality or is given as a schematic representation,

- a symbolic form, consisted in obtaining information through written or oral verbal presentation [4].

In the broadest sense, any form that represents content can be labeled as a medium, and based on such a definition, it can be concluded that all teaching and educational procedures and processes contain one media component. This component plays a very important role in the performance that learners will develop about reality. It is obvious that most of the forms of presentation of some teaching content represent a reduction or interpretation in relation to the real world. Cognition through models, schematics, or verbal symbols can lead students to inadequate or misconceptions about life and the world. Hence, the theory of learning emphasizes that teaching processes and models should be based as much as possible on real situations and solving real life problems. Of course, that is not always possible and it is not always necessary. On the one hand, there are scientific disciplines that by their nature are more oriented towards the world of symbols and abstract concepts. On the other hand, there are numerous situations in which students already have direct experiences about some parts of reality and therefore can learn well and acquire knowledge based on models, schematic representations or symbolic forms of presentation of teaching content. Such considerations lead us to two important epistemological and pedagogical questions: 
- Which media and what forms of content presentation are the most suitable for students to create appropriate representations and knowledge about the section of reality that is being processed?

- How to counteract the danger of creating inappropriate or misconceptions about reality through the media?

The answer to the first question constitutes a discipline called media didactics. The goal of media didactics is to establish the best ways to use the media in order to encourage and support the learning process. Media-didactic research was first conducted in the form of comparative research on the effects of different media on the success of learning success. The question of where in a teaching process a particular medium is most appropriate has led to the development of media taxonomy. Taxonomy refers to classification systems in which media are classified according to some of their features or characteristics. Such features can be a way of perceiving the media (visual, audio, audio-visual); form of encoding media messages (pictorial, schematic, symbolic); suitability for certain functions in teaching (attention, thinking, etc.) [5].

The answer to the second question explores the field of media education. In this discipline, the media themselves, together with their educational potentials and dangers, become the subject of teaching or educational reflection and re-examination. Media education gained special importance in the time of rapid development and influence, first of television, and later of the Internet, as media that shape not only the world of education, but also the way of living and thinking as a whole. As within media education, the media themselves become the subject of pedagogical research, all theories and results of general media theory are interesting for this area. These theories are often classified according to the elementary model of communication (transmitter, message, and receiver). Thus, we can distinguish between research of broadcasters (e.g. studies on the institutional conditions of media production), research of messages (e.g. analysis of media content) and research of receivers or recipients (e.g. studies on the impact of the media on the audience, everyday life, values and behavior of children and youth).

Media didactics and media education are not separate sciences, but areas that overlap. Taken together, these two disciplines make up media pedagogy. In the literature, both the term media and the term media pedagogy are used in several different meanings, but the mentioned definitions can be a simple and clear guide for further research [6].

\section{TECHNOLOGICAL AND SOCIAL CONTEXT OF NEW MEDIAAND THE INTERNET}

The problem of content acquisition, learning and education is becoming greater with the strong penetration of new media and the Internet, which should be respected, and which are first manifested through two approaches: the first approach refers to the issue of media form and it asks how new forms of media communication can be adequately described. The other approach does not emphasize new technical developments and new technical forms so much as subjective perceptions of new media and ways of handling new media. Thus, the long-established opposition of medio-centric perspectives and perspectives turned to reception, i.e. users, continues in the scientific study of the media.

From the long history of this opposition in the study of mass communication, we know that we must connect both problems with each other, the media issue of form with the problem of subjective handling of the media, which especially refers to the field of new media. New forms of media show what is technically possible, and subjective ways of using it show what can be realized [7].

New forms of internet communication open up, firstly, individual approaches to media offers, and secondly, increased individual possibilities of intervention and organization. From the recipients who observe, people become users who actively create text. There are new ways of information, communication and entertainment. In the field of information, particularly striking spaces for communication are those of the "wiki" type, primarily the online encyclopedia Wikipedia. In general, everyone can write and correct texts. This space provides the ability to cooperatively create, correct and actively update texts. Unlike the generalized offer of the media in the field of mass media, it is noticeable here that the texts are constantly spreading, but they are also always changeable. Unlike books, which all offer one identical text, Wikipedia offers - always only potentially - changeable texts. It is surprising that Wikipedia, despite these possibilities of organization, and thus interference and abuse, also provides very high quality information. It can be reasonably assumed that the possibilities of participating in the creation of determinants are much less used than the possibilities of reception, i.e. the use of Wikipedia [7].

Various forms of chats, forums, blogs, etc. have emerged in the field of communication. On this platform, students leave information about themselves and this information is used to organize many things in everyday life, 
such as looking for a roommate. In general, the boundary between private and public has become blurred, when choosing between restrained, business or personal access to the Internet.

In the field of entertainment, there are game worlds or virtual spaces like "Second Life", in which people meet to play and create artificial worlds together. Of course, the mentioned areas of information, communicative exchanges and entertainment cannot be clearly separated, moreover, there is a lot of overlap here [7].

It is certainly logical to describe these developments as shifting boundaries, especially the boundaries between producers (authors) and recipients (users) and the boundaries between private and public. Media sociology tries to shed light on such aspects of new forms of media communication. Here, in addition to the wellknown possibilities of feedback, intervention and organization, other specific features should be mentioned, such as the anonymity of the participants and the related depersonalization of communication. Internet communication is often not about connections between specific persons who are perceived, identified as persons, but about intertextuality, connections between texts. The written form of the text in communication creates an insurmountable difference towards oral conversation insofar as users do not interact with people, but with texts, ie. symbolic representations. Personalities thus become symbolic representations [8].

In this context, even chat, which is rated as very interactive, loses its innocence. Written conversations can be closer to social interactions in terms of share synchronization, but the technological environment and communication transfer can always be observed. Communication procedure and reception processes, i.e. understanding as well as additional communication are separated, and communicative technology convincingly comes to the fore here. When the contingency and non-transparency of communication increase in this way, different streams of meaning can arise for more people participating in the chat. This is just a matter of explaining on an example which observations and analyzes the debate on media competencies in the context of Web 2.0 would be based on from the media-sociological point of view.

In addition to the issue of media form, as mentioned, when studying new media, subjective observations and ways of acting of users as a starting point can be analyzed. The interactivity of new media and their importance stem initially from the user's active and practical handling. But what does the practical handling of new media, ie. the Internet mean? This is indicated by some results of an online study entitled: "Onliner 2007: Network of participation in the age of the Internet" [9]. As the title shows, there is interest in active participation in the network, which grew from 2006 to 2007 from one quarter to one third of Internet users. The great interest of half of the users between 14 and 19 years of age is a less surprising fact. Yet the share of active creators is relatively small: three-quarters of weblog users are just looking for information. In the case of Wikipedia, this relationship is even more pronounced, which is certainly surprising for many: only $6 \%$ of users have written an article or added information at least once, and it is similar with video portals. The number of active users who create content is disproportionately smaller. The basic motivation and value for many users is obviously not the ability to participate actively in the network, but to be able to consume attractive content [9]. It seems familiar, if we compare this with the primary success of the leading traditional media, television. From a media point of view, there is undoubtedly a profound shift in media from one-sided mass media to networked "interactive" media, from a user point of view it seems that new possibilities are still little used: Wikipedia or YouTube for example, look more like mass media, only content is created and designed by individual users. What is the cause of the great reluctance to participate actively, ie the difference between the media available potentials of active participation and the insufficient realization of these potentials, is of great importance for the scientific study of the media. The issue of media competence in the context of new media is not less important.

As in the field of traditional media research, we need a research strategy that avoids one-sidedness. It threatens when we focus only on the problem of media form or only on the contexts and processes of the subjective way of handling. The requirement to observe not only the problem of the form of new media but also the contexts and ways of handling new media is placed to the same extent in the field of interactivity. The possibilities of new communication through computers should not be viewed only at the level of media form and subjective perception and use, but also in given social contexts. New possibilities of online communication and online groups are "twisted" into social contexts and in terms of their advantages and disadvantages, they depend on these contexts "If the interaction within an online group is connected to a social network, which also exists in the offline world, then it is called the social embedding of online interaction in the networks of the offline world"[10]. 
This embedding plays a central role in organizing and improving online interactions. Typical problems here are the ability to control or also the ability to build trust. It is often helpful to use the possibility of direct interactions outside the Internet so as to solve such problems. Internet-based competence learning and acquisition processes depend on social conditions, which can be organized and shaped.

\section{MEDIA IN THE TIME OF THE INTERNET}

The rapid growth of Internet use among young people has been accompanied by controversial views on the importance of experience in cyberspace and their impact on adolescents. The Internet has long been an integral part of adolescents' media everyday life. According to research data in Germany, $95 \%$ of households with young people aged 12 to 19 are connected to the Internet. The number of Internet users is increasing proportionally. The use of the Internet by young people has reached a certain level in the last ten years, after which no increase is expected. From the perspective of the generation of parents, it seems that the higher intensity of Internet use that is present among young people is a problem [11].

The virtual worlds that young people roam around while sitting in front of their computers are completely foreign to most adults. However, observing the great dynamics with which the media everyday life has changed during the last decade, it becomes clear that the habits of the Internet use by young people and the experience with the media of their parents have nothing in common. Parents and teachers seem to think that using the Internet carries various risks. So it seems that there is a great danger of getting lost online due to the time it takes to use the internet.

Content that endangers youth (violence and pornography) as well as contact with anonymous Internet users who present themselves as their peers seem problematic. Already in the 90s, when the use of the Internet was much less widespread among young people, we have scientific papers that emphasize the risks and chances of using the Internet in the context of media socialization and identity development: Critics of Internet communication point out that the everyday concept of identity is suspended. Who wanders in the virtual, does not want authentic. Personal identity is an illusion in a world ruled by techno-social cyborg mechanisms [12].

On the other hand, proponents of new media believe that the Internet offers a bunch of personal experiences and an important understanding: I am the crowd. The pages on the Internet a new conception of a multiple but coherent identity illustrate in a particularly plastic way [12]. The Internet has become a metaphorical abode of the Self, and the user's identity is the result of the connections and relationships they establish. The Internet is a medium for expanding our intellectual and emotional identity in the age of globalization. According to some authors, Internet users who surf are at home, everywhere and nowhere. Children and young people become nomads on their own again. They can move from one point on Earth to another - and at the same time sit and live at home. Through this "new nomadism" humanity is being re-created and re-creating its world. As a technique used by today's youth on a daily basis, the Internet has proven to be a condition that determines the environment that determines the everyday life of a generation and its behavior. [12].

Bearing in mind the developmental tasks of young people, it can be expected that information and communication technologies for building new relationships could be functional, especially in relation to increased mobility options.

If we look at the historical development of the media, we can notice the flow of completely autonomous media, such as books or newspapers, through diffuse media that operate with the help of wave frequencies and cable connections (eg radio or television), through communication media such as the telephone, to interactive media as they emerge in the age of the Internet. Media communication on the global network has the following characteristics:

- multimedia

- hypertextuality

• non-existence of "gatekeeper"

- elasticity interactivity [13].

While traditional mass media use one or two dominant ways of conveying messages, multimedia involves combining text, images, graphics, animation, audio and video. Hypertextuality allows media content to be accessed in any way, without a firmly defined hierarchical structure. The Internet is an open network, in which no one but the computer determines the way in which the information will be transmitted. By elasticity we mean the fact that the Internet allows both instant communication (live) and multiple variations of delayed broadcasting of media content. Finally, interactivity implies a model of interconnected and mutually induced communication, which fundamentally changes the relationship between the media and the audience [13]. 
The first electronic online edition of the daily newspaper appeared in the spring of the 1990s, when the Chicago Tribune became available online. While the first electronic newspapers were content to be a digital copy of a paper edition, much more independent and creative sites soon emerged with the advantages offered by the network: interactivity, hypertextuality, openness to other digital sources of information [13].

Continuous updating of newspaper sites and interactions with readers in real time enables the personalization of media to the extent that they become the collaboration between producers and audience. Personalized and interactive multimedia communication changes the very essence of mass media: Compared to traditional, cyber journalism - as science fiction fans like to call it - takes the role of gatekeeper to extremes: The network is a huge information supermarket, where news gathering often resembles collage and hypertext connecting various sites of news agencies, television, business companies, public administration, with the scarce space left for writing and for individual creativity. There is a risk that the Internet will become a place of post-journalism, trapped in itself, where the encounter with reality remains in the background and always takes place through someone's mediation.

Another great novelty of monitoring information and learning on the Web is interactivity: the process of content personalization develops two-way information channels between those who post content and recipients, readers. This creates a possible remedy for the social opacity created by the abundance of supply, leaving wider freedom of choice to users, but also by renouncing the one who offers content from his own historical role of guide and orientation. Newspapers risk adapting to the supermarket formula, arranging ever richer shop windows, but avoiding the possibility of choice.

\section{CONCLUSION}

Digitization of media messages and integration of modern forms of communication, through the synergy of mobile phones, digital cameras, television, computers and the Internet, destroy the traditional media order and enable the emergence of the so-called civic access to content. It is a trend that, instead of professionals, media content is generated by technologically equipped amateurs who who happened to be on the site of an important event. Even traditional, institutional media, such as the BBC, realized the potential of a new kind of journalism, encouraging users on their site to send their photos and videos to the newsroom, with the message: Important things may happen anywhere and anytime we we want you to be our eyes. Once something appears on the Internet, it can multiply endlessly, it allows people to see what they want to see. 'Broadcasting', the traditional model of 'old' media, is slowly but surely replacing 'clicking': instead of 'receiving' (the official film of execution), content is now 'taken' (a recording of the hanging taken by a mobile phone). The unexpected effect of technology, which increased state surveillance capabilities to Orwellian borders and exacerbated Big Brother syndrome, is the fact that we no longer have to be just objects of control: armed with digital cameras, mobile phones and the Internet - we are also watching them.

Marshall McLuhan predicted that the development of electronic media would unite the world into one big global village. As soon as technology expands our senses, there is a new translation and revaluation of culture, at the speed with which new technology is perfected and marks the world of reality. McLuhan's prediction has been fully realized. Something that happened in any part of the world almost simultaneously becomes news that can affect all people on the planet.

However, even the ingenious McLuhan could not have foreseen all the speed and depth of the changes brought about by the Internet and new communication and media technologies. These are new phenomena such as digitalization, media integration and interactivity, which call into question the very concept of mass media. The Internet opened up new perceptual and cognitive possibilities, set different standards in the preparation, transmission and reception of media messages, and opened up unimagined perspectives on communication. Of course, the Internet brought new controversies, starting from the question of whether it is a medium in the full sense of the word, or the Internet is just a virtual space in which all media are united, to the question of responsibility for the quality and reliability of online information.

\section{REFERENCES}

[1] M. Mekluan, Poznavanje opštila čovekovih produžetaka, Beograd: Prosveta, 1971.

[2] R. Debre, Uvod u mediologiju, Beograd: Clio, 2000.

[3] D. Kelner, Medijska kultura, Clio, 2004.

[4] G. Tulodziecki, "Medien in Unterricht und Erziehung," in Pädagogik, München, Oldenburg, 2001. 
[5] M. Andevski, J. Arsenijević and M. Maljković, "Computer in media-didactic discourse," in Proceedings of 6th International Technology, Educational and Development Conference, Valencia, 2012.

[6] H. Moser, Einführung in die Medienpädagogik, Wiesbaden, 2006.

[7] M. Andevski, J. Arsenijević and M. Maljković, "From the First "Click" to Virtual University," in Proceedings of eMoNT 2012, Vrnjačka Banja, 2012.

[8] M. Andevski, T. Kliček and I. Šćepanović, “Communication through Internet and identity development of the Young.," in Proceedings of Scientific research "Knowledge, Education, Media", Novi Sad, 2011.

[9] M. Radojković and B. Stojković , Informacionokomunikacioni sistremi, Beograd: Clio, 2009.

[10] H. Schelhowe, Technologie, Imagination and Lernen, Münster: Waxmann, 2007.

[11] D. Gocini, Istorija novinarstva, Beograd: Clio, 2001.

[12] T. Brabazon, The University of Google: Education in a (post) information age, Aldershot: Ashgate, 2007.

[13] M. Mekluan, Gutenbergova galaksija, Beograd: Nolit, 1973. 